Numer i cal Si mul at i on of Snow Mel ting on Pavement Surface wi th Heat Di ssi pat i on Pi pe Enbedded

\begin{tabular}{|l|l|}
\hline 著者 & $\begin{array}{l}\text { NAGAl N ro, M YAMTO Shi genobu, N SH WAK } \\
\text { Nasaya, TAKEUCH Nasanor i }\end{array}$ \\
\hline $\begin{array}{l}\text { j our nal or } \\
\text { publ i cat i on ti tl e }\end{array}$ & Heat Tr ansf er - Asi an Resear ch \\
\hline vol une & 38 \\
\hline number & 5 \\
\hline page r ange & $313-329$ \\
\hline year & $2009-07$ \\
\hline URL & ht t p: //hdl . handl e. net /10098/2105 \\
\hline
\end{tabular}




\section{Heat Transfer- Asian Research}

Paper No. B-08-09

Paper title:

Numerical Simulation of Snow Melting on Pavement Surface with Heat Dissipation Pipe Embedded

Author(s):

Niro Nagai ${ }^{* 1}$, Shigenobu Miyamoto ${ }^{* 2}$, Masaya Nishiwaki ${ }^{* 3}$ and Masanori Takeuchi ${ }^{* 1}$

*1 : Department of Mechanical Engineering, University of Fukui, Japan

*2 : Snow Management \& Construction Technology Research Center of Fukui Prefecture, Japan

*3 : Hitachi Electronics Services Co., Ltd., Japan

Originally published in

Trans JSME, Ser B, 74, 739, 640-647, 2008.

Translated by

Niro Nagai, Department of Mechanical Engineering, University of Fukui, 3-9-1 Bunkyo, Fukui, 910-8507, Japan.

English-checked by

Eckhard MS. Hitzer, A part-time teacher of English, Department of Applied Physics, University of Fukui, Fukui, 910-8507, Japan.

Total number of manuscript pages :

Number of cover pages :

Number of text pages :

Number of pages for Figure and Table Captions :

$\frac{01}{15}$

Number of pages for figures and tables :

14

Number of Figures :

14

Figures are (included) in the electronic file.

Black/white print is enough for all the figures.

Number of Tables : $\frac{01}{c \text { file. }}$

File name of attached electronic file (MsWord) : $\quad$ HTAR B-08-09 Nagai

Figures and tables are (included) in the electronic file. 


\title{
Numerical Simulation of Snow Melting on Pavement Surface with Heat Dissipation Pipe Embedded
}

\author{
Niro Nagai ${ }^{* 1}$, Shigenobu Miyamoto ${ }^{* 2}$, Masaya Nishiwaki ${ }^{* 3}$ and Masanori Takeuchi ${ }^{* 1}$ \\ *1 : Department of Mechanical Engineering, University of Fukui, Japan \\ *2 : Snow Management \& Construction Technology Research Center of Fukui \\ Prefecture, Japan \\ *3 : Hitachi Electronics Services Co., Ltd., Japan
}

\begin{abstract}
A programmed software was developed in order to numerically simulate time variation of temperature field and snow depth around a pipe-in-pile snow-melting system, using meteorological data. The system utilized underground piles as heat exchanger between underground soil and water flowing inside the piles. The water was pumped into heat dissipation pipes embedded beneath pavement surface, on which snow melted. Unsteady three-dimensional heat conduction inside the pavement and the underground soil was numerically solved. On the surface, heat balance of conduction, convection and radiation was considered. Snow fall depth was estimated by rainfall weather data, ratio of snowfall to rainfall, and dry density of snowfall. For simulating snow layer, unsteady one-dimensional heat conduction was solved while incorporating partial absorption of solar radiation. Experiments for measuring time variation of
\end{abstract}


temperature field and snow depth around the system were conducted for verification of the software. The obtained simulation results showed good agreements with experimental data, demonstrating utility and validity of the software.

Key words: Geothermal Energy, Snow Melting, Numerical Simulation, Heat Transfer, Heat Transfer Design

\section{Introduction}

Recently, the importance of usage and its promotion of renewable energy has been increasing, and then research and development of geothermal energy utilization has been active [1]. Geothermal energy is largely classified into relatively high temperature heat source of deep part and low temperature heat source of shallow part. The low temperature heat source of shallow part which is generally within $200 \mathrm{~m}$ depth from ground keeps almost constant temperature, $10 \sim 20{ }^{\circ} \mathrm{C}$ for Japan, through a year. Therefore, the low temperature heat source of shallow part can be easily used for air conditioning and snow melting. For example, Ikegami et al. [2] conducted numerical analysis of geothermal utilization system consisting of heat pump, underground heat exchanger pipe and thermal load of air conditioning. They presented optimization method depending on the number and length of underground heat exchanger pipes. Meanwhile, snow melting technique using geothermal energy is recognized as one of snow melting methods that are important for countermeasure of snow damage. The snow melting technique using geothermal energy has been paid much attention as ecological and low cost method, since there is no worry about ground subsidence 
frequently caused by snow melting system by spraying of underground water, and this technique utilizes renewable natural energy.

The authors have been invented and developed a new snow melting technique using geothermal energy, named as "pipe - in - pile snow melting system” [3], schematically shown in Fig.1. In this system, concrete foundation piles for building serve as heat exchanger to underground. These underground piles and heat dissipation pipes embedded beneath pavement surface are filled with water, and the water circulates in the system by pump, working as heat medium. Furthermore, this system has been applied to snow melting and freeze proofing of bridge surface using foundation piles of bridge [4].

In order to design and predict snow melting ability of the system mentioned above, it is very important to make and verify numerical simulation software calculating time variation of temperature field and snow depth around the system. For simulating the system through a year, the following all items should be linked together.

i) unsteady heat conduction of underground soil around the piles and pavement around the heat dissipation pipes

ii) heat transfer of both between water in the piles and the underground soil and between water in the heat dissipation pipes and the pavement

iii) heat transfer on the pavement surface and snow depth change, evaluated by meteorological data such as snowfall, rainfall, solar irradiation, sky radiation, atmospheric temperature and wind velocity

This paper aims to demonstrate the detailed method of the numerical simulation stated above, and to show validity of the simulation by comparing with experimental data.

\section{[ Figure 1 ]}




\section{Nomenclature}

$c: \quad$ specific heat, $\mathrm{J} /(\mathrm{kg} \cdot \mathrm{K})$

$h: \quad$ convective heat transfer coefficient, $\mathrm{W} /\left(\mathrm{m}^{2} \cdot \mathrm{K}\right)$

$h_{D}: \quad$ mass transfer coefficient of water vapor in air, $\mathrm{m} / \mathrm{s}$

$h_{S}$ : heat transfer coefficient between pavement surface and accumulated snow, $\mathrm{W} /\left(\mathrm{m}^{2} \cdot \mathrm{K}\right)$

$I$ : $\quad$ incident solar radiation, $\mathrm{W} / \mathrm{m}^{2}$

$J: \quad$ thermal radiation, $\mathrm{W} / \mathrm{m}^{2}$

$m_{r}: \quad$ rainfall mass flux, $\mathrm{kg} /\left(\mathrm{m}^{2} \cdot \mathrm{s}\right)$

$q_{m}: \quad$ latent heat of solidification, $\mathrm{J} / \mathrm{kg}$

$q_{r}: \quad$ latent heat of evaporation of water, $\mathrm{J} / \mathrm{kg}$

$t: \quad$ time, $\mathrm{s}$

$T: \quad$ temperature, ${ }^{\circ} \mathrm{C}$

$u: \quad$ velocity, $\mathrm{m} / \mathrm{s}$

$w$ : mass concentration of water vapor

$x: \quad$ coordinate axis of horizontal directions, $\mathrm{m}$

$y: \quad$ coordinate axis of horizontal directions, $\mathrm{m}$

$z: \quad$ coordinate axis of gravitational direction, $\mathrm{m}$

$z_{S}: \quad$ thickness of snow layer, $\mathrm{m}$

$\alpha: \quad$ solar absorptivity

$\varepsilon: \quad$ emissivity

$\lambda: \quad$ thermal conductivity, $\mathrm{W}(\mathrm{m} \cdot \mathrm{K})$

$\rho: \quad$ density, $\mathrm{kg} / \mathrm{m}^{3}$ 


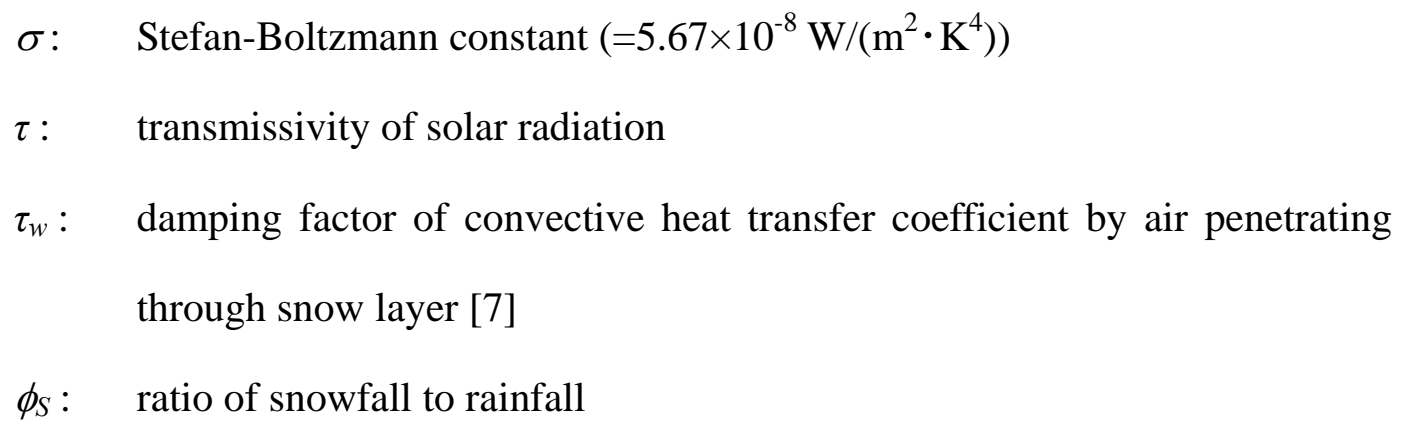

Subscripts
$a: \quad$ surrounding air
$D$ : $\quad$ water vapor.
$G$ : $\quad$ pavement surface
$r: \quad$ rainfall
$S: \quad$ accumulated snow or snowfall

\section{Method of Numerical Simulation}

\subsection{Simulation of the whole system}

As to heat transfer inside both underground soil around the piles and pavement around the heat dissipation pipes, unsteady three dimensional heat conduction equation as the following was solved numerically.

$$
c \rho \frac{\partial T}{\partial t}=\lambda\left(\frac{\partial^{2} T}{\partial x^{2}}+\frac{\partial^{2} T}{\partial y^{2}}+\frac{\partial^{2} T}{\partial z^{2}}\right)
$$

here, $c$ : specific heat $[\mathrm{J} /(\mathrm{kg} \cdot \mathrm{K})], \rho$ : density $\left[\mathrm{kg} / \mathrm{m}^{3}\right], \lambda$ : thermal conductivity $[\mathrm{W} /(\mathrm{m} \cdot \mathrm{K})]$, $T$ : temperature $\left[{ }^{\circ} \mathrm{C}\right], t$ : time $[\mathrm{s}], x, y$ : coordinate axis of horizontal directions $[\mathrm{m}], z$ : coordinate axis of gravitational direction [m]. 
The pavement around the heat dissipation pipes generally consists of multi layers with different thermal physical properties such as tile, concrete, asphalt, and subbase. Therefore, for calculation of the pavement, each physical property in Eq. (1) was assigned different value in the different layer. As to calculation of underground soil around the piles, each physical property in Eq.(1) was set to one averaged value in the whole calculation domain.

The numerical solution of Eq. (1) was done basically by finite difference method. Inside the pavement, several centimeters below the ground surface, heat dissipation pipes with circular cross section were embedded. Therefore, boundary-adoptive grid system was used for finite difference grids of cross section orthogonal to the heat dissipation pipes. For the finite difference grids along the pipes, grids with non-uniform spacing were used.

The boundary condition on the pavement surface without snow cover was as the following equation.

$$
\begin{aligned}
\left(-\lambda \frac{\partial T}{\partial z}\right)_{z=0}= & I \alpha_{G}+J_{G}+h_{a}\left(T_{a}-T_{G}\right)+m_{r} c_{r}\left(T_{r}-T_{G}\right) \\
& +h_{D} \rho_{a}\left(w_{a}-w_{G}\right)\left\{q_{r}+c_{D}\left(T_{a}-T_{G}\right)\right\}
\end{aligned}
$$

here, $I$ : incident solar radiation on pavement surface $\left[\mathrm{W} / \mathrm{m}^{2}\right], \alpha_{G}$ : solar absorptivity of pavement surface, $J_{G}$ : net heat transfer of infrared radiation $\left[\mathrm{W} / \mathrm{m}^{2}\right], h_{a}$ : convective heat transfer coefficient between pavement surface and air $\left[\mathrm{W} /\left(\mathrm{m}^{2} \cdot \mathrm{K}\right)\right], h_{D}$ : mass transfer coefficient of water vapor in air $[\mathrm{m} / \mathrm{s}], m_{r}$ : rainfall mass flux $\left[\mathrm{kg} /\left(\mathrm{m}^{2} \cdot \mathrm{s}\right)\right], q_{r}$ : latent heat of evaporation of water $[\mathrm{J} / \mathrm{kg}], w$ : mass concentration of water vapor, $\varepsilon$ : emissivity of pavement surface, $\sigma$. Stefan-Boltzmann constant $\left(=5.67 \times 10^{-8} \mathrm{~W} /\left(\mathrm{m}^{2} \cdot \mathrm{K}^{4}\right)\right)$. For subscripts, $a$ : surrounding air, $G$ : pavement surface, $r$ : rainfall, $D$ : water vapor. 
Each term in right-hand side denotes absorbed heat from solar radiation, net heat transfer by infrared thermal radiation, convection heat transfer between surrounding air and the pavement surface, sensible heat conveyed by rainfall, and heat transfer associated with water vapor mass transfer by dew condensation and evaporation, respectively. Net heat transfer by infrared thermal radiation, $J_{G}$, can be expressed as difference between atmospheric emission, $J_{a}$, and ground emission as follows.

$$
J_{G}=\varepsilon_{G}\left\{J_{a}-\sigma\left(T_{G}+273.15\right)^{4}\right\}
$$

Convective heat transfer coefficient between pavement surface and air, $h_{a}$, was estimated by the following Jurges’s empirical formula [5].

$$
h_{a}= \begin{cases}3.95 u_{a}+5.58 & \left(u_{a} \leq 4.8 \mathrm{~m} / \mathrm{s}\right) \\ 7.14 u_{a}^{0.78} & \left(u_{a}>4.8 \mathrm{~m} / \mathrm{s}\right)\end{cases}
$$

here, $u_{a}$ is wind velocity $[\mathrm{m} / \mathrm{s}]$, which can be given by meteorological data.

Mass transfer coefficient of water vapor in air, $h_{D}$, was estimated from convective heat transfer coefficient, $h_{a}$, by the heat and mass transfer analogy, so-called Lewis's relation $[6]$.

The boundary condition on the pavement surface with snow cover was as the following equation.

$$
\left(-\lambda \frac{\partial T}{\partial z}\right)_{z=0}=I \tau \alpha_{G}+h_{a} \tau_{w}\left(T_{a}-T_{G}\right)+h_{S}\left(T_{S}-T_{G}\right)
$$

here, $\tau$ : transmissivity of solar radiation through snow layer, $\tau_{w}$ : damping factor of convective heat transfer coefficient by air penetrating through snow layer [7], $h_{s}$ : heat transfer coefficient between pavement surface and accumulated snow $\left[\mathrm{W} /\left(\mathrm{m}^{2} \cdot \mathrm{K}\right)\right]$. For subscript, $S$ : accumulated snow. 
Each term in right-hand side denotes absorbed heat from solar radiation transmitting through snow layer, convection heat transfer between pavement surface and air penetrating through snow layer, and heat transfer between pavement surface and accumulated snow, respectively.

As the boundary condition of inner surface of heat dissipation pipes, convective heat transfer coefficient between the surface and heat medium, water, was given. The heat transfer coefficient was changed according to flow situation: water flowing or still. The representative temperature of heat medium inside was mean temperature at cross section. Only the temperature distribution along flow direction was calculated.

As to arrangement of heat dissipation pipes, water circuits of U-type and I-type arrangement [9] were considered. Temperature distribution inside pavement surface was calculated only for calculation domain including one water circuit, since temperature field inside pavement surface is symmetrical for each water circuit.

\subsection{Simulation of snow layer on pavement surface}

In case of snow cover on pavement surface, snow layer just above heat dissipation pipes shall be thin, while it should be thicker above region between heat dissipation pipes. Furthermore, even just above heat dissipation pipes, snow layer above inlet of heat medium, water, shall be thin, while it should be thicker above outlet. It is rather difficult and needs much calculation time for simulate unsteady three-dimensional temperature field of snow layer whose thickness varies momentarily. In this paper, unsteady one-dimensional temperature filed of snow layer was calculated, neglecting heat conduction of horizontal directions inside snow layer, since thermal conductivity of snow layer is relatively small, less than $0.1 \mathrm{~W} / \mathrm{m} \cdot \mathrm{K}$. The unsteady one-dimensional heat 
conduction equation, as shown in Eq. (6), was solved for the snow layer of all calculation grids on the pavement surface.

$$
c_{S} \rho_{S} \frac{\partial T_{S}}{\partial t}=\lambda_{S} \frac{\partial^{2} T_{S}}{\partial z^{2}}+I \alpha_{S}
$$

The 2nd term in right-hand side denote absorbed solar heat in the snow layer

The boundary conditions of snow layer was as the followings, here $z_{S}$ means thickness of snow layer [m], the point of $z=0$ denotes the pavement surface and $q_{m}$ means latent heat of solidification $[\mathrm{J} / \mathrm{kg}]$.

$$
\begin{aligned}
\left(-\lambda_{S} \frac{\partial T_{S}}{\partial z}\right)_{z=z_{S}}= & I \alpha_{S}+J_{S}+h_{a}\left(T_{a}-T_{S}\right)+m_{r} c_{r}\left(T_{r}-T_{S}\right) \\
& +h_{D} \rho_{a}\left(w_{a}-w_{S}\right)\left\{q_{r}+q_{m}+c_{D}\left(T_{a}-T_{S}\right)\right\} \\
\left(-\lambda_{S} \frac{\partial T_{S}}{\partial z}\right)_{z=0}= & h_{S}\left(T_{S}-T_{G}\right)
\end{aligned}
$$

Time variation of thickness of snow layer, i.e. amount of snow melting, was calculated as the following steps.

i) Assuming that snow did not melt, temperature filed of snow layer was calculated.

ii) Among all calculation grids in snow layer, temperature of grids which was higher than melting point, $0{ }^{\circ} \mathrm{C}$, was set to melting point, and again temperature filed of snow layer was calculated.

iii) Using calculated temperature field, heat input from top surface $\left(z=z_{S}\right)$ and bottom surface $(z=0)$ was estimated.

iv) As to temperature calculated by the heat input estimated at step iii), when temperature where its value was set to melting point did not exceed the melting point or when temperature where its value was calculated under the melting point 
exceeded the melting point, temperature field was re-calculated after revision of temperature.

v) After temperature field was finally calculated, heat input from top surface and bottom surface was obtained. As to temperature calculated by the heat input finally estimated, when temperature exceeded melting point, snow was numerically judged to melt just as much as compensation of temperature excess.

vi) Melting snow shall be water. In this paper, the water was assumed to be immediately exhausted from snow layer, not penetrating and staying inside snow layer nor re-freezing. Fresh snow was considered to accumulate on snow layer at snowfall temperature, i.e. wet bulb temperature.

The numerical solution of Eq. (6) was also done by finite difference method. The finite difference grids were re-arranged after amount of melting snow and fresh snow was calculated and thickness of snow layer was newly decided according to process i) vi).

It is necessary for estimating correct amount of snow melting to consider temperature distribution of snow layer of vertical direction. Especially, it becomes more important when snow layer is thicker and atmospheric temperature is lower, since upper layer temperature is below melting point even though lower layer temperature is nearly melting point. If temperature of whole snow layer was expressed by one representative value, convective heat transfer from top surface of snow layer to surrounding air shall be overestimated, resulting in underestimate of snow melting.

The ratio of snowfall to rainfall, $\phi_{S}$, was estimated by Eq. (9) using rainfall temperature, $T_{r}$, [10] which is equal to wet bulb temperature , as shown in Fig. 2. 


$$
\begin{array}{ll}
T_{r}>4 ; & \phi_{S}=0 \\
4 \geq T_{r} \geq 1.1 ; & \phi_{S}=0.5 \times \exp \left[-2.2 \times\left(T_{r}-1.1\right)^{1.3}\right] \\
1.1>T_{r} ; & \phi_{S}=1-0.5 \times \exp \left[-2.2 \times\left(1.1-T_{r}\right)^{1.3}\right]
\end{array}
$$

\section{[ Figure 2]}

Experimental data of dry density of snowfall, $\rho_{S}\left[\mathrm{~g} / \mathrm{cm}^{3}\right]$, are shown in Fig.3. These data was measured from 1998 to 2001 at capital cities of seven snowy prefectures in Japan. The dry density was estimated by snowfall thickness measured at every several hours and rainfall converted from snowfall. From Fig. 3, the dry density was expressed by the following approximate equation as a function of wet bulb temperature.

$$
\begin{array}{ll}
T_{r}>-2 ; & \rho_{S}=0.0169 \times T_{r}{ }^{2}+0.0655 \times T_{r}+0.1335 \\
-2 \geq T_{r} ; & \rho_{S}=0.0044 \times T_{r}+0.079
\end{array}
$$

\section{[Figure 3 ]}

Since rainfall temperature varies with time, dry density of snowfall also changes with time. In this numerical simulation, dry density of snowfall was assumed to be constant during one calculation time step, where its value was averaged during the time step. Dry density of snowfall was calculated from each summation of mass and volume of snowfall estimated by Eq. (9) and (10), using meteorological data of every hour.

Figure 4 demonstrates comparison on accumulated snowfall depth between observed value at Fukui Local Meteorological Observatory and calculated value by Eq. (9) and (10). The calculated value of accumulated snowfall depth shows favorable agreements with that of observed value, except around Jan. 29, 2001. As judged from Fig. 2, when wet bulb temperature ranges between $-0.4^{\circ} \mathrm{C}$ and $2.6^{\circ} \mathrm{C}$, rainfall is mixed with snowfall and estimation of snowfall ratio has relatively large error. Furthermore, at the same web bulb temperature range, dry density of snowfall becomes very sensitive to web bulb temperature as shown in Fig. 3. Around Jan. 29, 2001, wet bulb temperature 
ranged between $0.4^{\circ} \mathrm{C}$ and $1.2^{\circ} \mathrm{C}$, relatively higher temperature as snowfall, and the snowfall at that time contained much rainfall which may caused discrepancy between observed value and calculated value of snowfall depth. Except specific conditions such as around Jan. 29, 2001, the calculation method of snowfall depth using Eq. (9) and (10) was found to be accurate and useful.

\section{[ Figure 4]}

\section{Experimental System for Verification}

For verification of the numerical simulation stated in the last chapter, experimental system of snow melting with geothermal energy as shown in Fig. 1 was built in Fukui city. The experimental system consisted of one heat exchanger pile, pavement with heat dissipation pipes embedded as shown in Fig. 5, piping system, and snow fall sensor. The heat exchanger pile buried into underground was made of concrete, and its size was inside diameter $290 \mathrm{~mm}$, outside diameter $450 \mathrm{~mm}$, and $22 \mathrm{~m}$ length. The snow fall sensor detected snow cover on the pavement surface, which controlled the pump of piping system.

\section{[ Figure 5 ]}

The pavement was $0.9 \mathrm{~m} \times 14.0 \mathrm{~m}$ with $150 \mathrm{~mm}$ thickness, made of silica rock aggregate concrete. The surroundings and base surface of the pavement were covered by heat insulator, styrene foam board, as shown in Fig. 5. Heat dissipation pipes, SGP 15A type, were embedded inside the pavement with covering thickness of $40 \mathrm{~mm}$. The heat dissipation pipes were arranged in U-type with $150 \mathrm{~mm}$ pitch. At the header portion of water supply and drainage of heat dissipation pipes, Pt resistance thermometers were set for measuring inlet and outlet water temperature. For measuring temperature field of 
the pavement, T-type thermocouples were set as shown in Fig. 5. The snow fall sensor was embedded near the pavement surface around U-turn point of heat dissipation pipes. The snow fall sensor detected and controlled the pump every 10 minutes.

From Jan. 1 to March 17, 2001, snow melting operation was conducted where the pump was electronically switched on if the snow fall sensor detected snow cover on the pavement surface. During the operation period, Fukui city had heavy snowfall from Jan. 13 to Jan. 18 after an interval of 15 years. Maximal snow depth at natural state reached $93 \mathrm{~cm}$.

Meteorological data used in the numerical simulation were downloaded from Japan Meteorological Business Support Center [11]. The data were observed and measured at Fukui Local Meteorological Observatory, $450 \mathrm{~m}$ apart from the experimental site, which included air temperature, amount of rainfall, wind velocity corresponding to value at $1.5 \mathrm{~m}$ from ground, water vapor pressure, solar radiation, and amount and kind of cloud. Thermal properties such as thermal conductivity of ground, pile and pavement were measured if necessary. Thermal properties and characteristic values used in the simulation are listed in Table 1.

\section{[ Table 1 ]}

The time step for the numerical simulation was set to five minutes. However, the time step was subdivided at the beginning of both pumping operation and inversion of pumping direction, such as for several time steps to be calculated during heat medium making a circuit of heat dissipation pipes.

In the numerical simulation, judgment of pumping time did not depend on experimental data. Pumping was triggered on when remaining snow depth at the position above snow fall sensor was calculated to exceed $0.05 \mathrm{~cm}$. 


\section{Verification of Numerical Simulation}

As to heavy snowfall period, simulation results of outlet water temperature of heat dissipation pipes are compared with measured data in Fig. 6. From Jan. 14, 12:30 PM, water flow direction inside heat dissipation pipes was inverted every two hours by motor-operated valve. Therefore, data in Fig. 6 means inlet and outlet water temperature alternately changed by every two hours. The simulation results in Fig. 6 also correspond to this situation. At several times, there were malfunctions of the snow fall sensor that pumping had ceased even when there was snow fall. At those times, water flow was also stopped in the numerical simulation. Fig. 6 shows that simulation results of outlet water temperature and starting times of pumping agree well with measured data. A little discrepancy between simulation and measurement can be seen at around times of pumping stop where pumping stop time of simulation results is slightly earlier than that of measured value.

\section{[ Figure 6]}

Averaged heat dissipated from heat dissipation pipes per unit pavement surface is plotted in Fig. 7 during heavy snowfall period. The heat dissipated from heat dissipation pipes was estimated by inlet and outlet temperature and flow rate of water. At the beginning of pumping operation, water from the heat exchanger pile of relatively higher temperature was pumped to heat dissipation pipes, resulting in higher heat flux, 200 $400 \mathrm{~W} / \mathrm{m}^{2}$. After water made a circuit in the piping system, the heat flux showed almost constant value, $100 \sim 150 \mathrm{~W} / \mathrm{m}^{2}$. Figure 8 demonstrates integrated heat dissipated from heat dissipation pipes per unit pavement surface during whole tested period. From these figures, simulation results on averaged heat flux and integrated value show good agreements with measured data. 


\section{[Figure 7]}

\section{[Figure 8]}

As to heavy snowfall period, simulation results of remaining snow depth around the middle point of water flowing direction of heat dissipation pipes are compared with measured data in Fig. 9. In the simulation, amount of remaining snow was calculated in mass, so in Fig. 9, the mass value was converted to volume using averaged dry density of snowfall, $0.118 \mathrm{~g} / \mathrm{cm}^{3}$, through the whole period. Figs. 10(a) and 10(b) show an observed situation and simulation results of remaining snow depth on pavement surface at Jan. 14, 0 AM. At this time, water flow direction did not inverted, so the remaining snow depth above inlet of heat dissipation pipes was smaller than that that above outlet. In addition, the remaining snow depth on the region between heat dissipation pipes was larger than that of just above heat dissipation pipes, so the shape of remaining snow depth at cross section of axial direction seemed like an arch type. As to these situations on remaining snow depth, the simulation results agreed well with experimental results.

\section{[ Figure 9]}

\section{[ Figure 10]}

However, when remaining snow depth became large, as shown in Fig. 11(a), the difference of remaining snow depth between maximum and minimum point became relatively small, while the simulation results at the same time showed different shape of remaining snow depth as shown in Fig. 11(b). In the simulation, as snow melting proceeded, the pavement surface appeared just above the heat dissipation pipes, and much snow remained on the surface between the heat dissipation pipes. Therefore, a steep peak of remaining snow depth could be seen as shown in Fig. 11(b). In the experiment, such a steep peak did not appear, instead snow melted almost uniformly on the pavement surface, resulting in delay of exposure of the pavement surface compared 
with the simulation. This difference is due to both "snow bridge" formed just above the heat dissipation pipes and "collapse" of snow peak. The snow bridge made air gap between the pavement surface and snow layer, which was not simulated in this paper. This difference was only during heavy snow fall, so checking through the whole period, the difference did not expanded so large, as shown in Fig. 8.

\section{[ Figure 11]}

At the time of Fig. 11(a), 0 AM of Jan. 16, 2001, natural snow depth reached 75 $\mathrm{cm}$, and at the next day, 3 AM of Jan. 17, it increased to $93 \mathrm{~cm}$. This new snow melting system using geothermal energy, named as “pipe - in - pile snow melting system”, was proved to have an ability to deal with such a heavy snowfall.

Figure 12 demonstrates simulation results of isotherm at cross section of the pavement at the same time with Fig. 10. Figure 12(a) corresponds to cross section $0.5 \mathrm{~m}$ apart from inlet and outlet of heat dissipation pipes, while Fig. 12(b) shows cross section $0.5 \mathrm{~m}$ apart from U-turn edge of heat dissipation pipes. In Fig. 12(a) and (b), there can be seen two isotherms which have peak values on the inlet and outlet surface of heat dissipation pipes. Figure 12(a) demonstrates higher temperature field around inlet heat dissipation pipes than that around outlet pipes, resulting in better snow melting ability above inlet heat dissipation pipes as shown in Fig. 10. On the other hand, at cross section around U-turn edge as shown in Fig. 12(b), temperature field becomes almost bilateral symmetry since water temperature in both heat dissipation pipes are almost the same. These simulation results are logical and have consistency with experimental results.

\section{[ Figure 12]}

The pavement surface temperature at above the center part of heat dissipation pipes are shown in Fig. 13. While the pavement surface was covered with snow, the 
surface temperature designate $0.4 \sim 0.7^{\circ} \mathrm{C}$, slightly higher than melting point. On the other hand, while there was no snow, the surface temperature rose to $10 \sim 20{ }^{\circ} \mathrm{C}$ during daytime due to solar radiation, and decreased to around $0{ }^{\circ} \mathrm{C}$ during nighttime due to thermal radiation. This tendency matched very well in both simulation and experimental results. Instead that the surface temperature of simulation results shows $2 \sim 5{ }^{\circ} \mathrm{C}$ higher than that of experimental data when the surface temperature became high during daytime, simulation results agree well on the whole with experimental data quantitatively.

\section{[ Figure 13]}

Figure 14 demonstrates water temperature inside the heat exchanger pile at $2.9 \mathrm{~m}$ depth for the whole period. After thermal load for snow melting began at the pavement, water flowed to heat dissipation pipes, resulting in rapid decrease of water temperature inside the pile as shown in Fig. 14. However, after the thermal load stopped and water flow ceased, water temperature inside the pile gradually recovered by heat conduction from surrounding soil. This tendency matched very well qualitatively and quantitatively in both simulation and experimental results.

\section{[ Figure 14]}

Summarizing verification results, this numerical simulation method was found to be able to calculate reasonably heat transfer around the pavement and the pile. Therefore, it can be said that snow melting ability and snow remaining situations of this system are predictable by this simulation method using meteorological data.

\section{Conclusions}


As to a new snow melting system using geothermal energy, named as "pipe - in pile snow melting system”, a simulation method was developed for calculating heat transfer around the pavement and the pile and for simulating snow melting situation on the pavement surface using meteorological data. As a result, the simulation results well agreed with experimental data, demonstrating that snow melting ability and snow remaining situations of this system are preferably predictable by this simulation method. 


\section{Literature Cited}

1 Nagano, K., Ground thermal energy systems in Japan -evaluation of actual GSHPs in Hokkaido, Journal of the Heat Transfer Society of Japan, Vol.46, No.196, (2007), pp.42-48.

2 Ikegami, Y. et al., Performance analysis of ground heat source utilization system using heat pump, Transactions of the Society of Heating, Air- Conditioning and Sanitary Engineers of Japan, No.100, (2005), pp.1-8.

3 Takeuchi, M. et al., Development and numerical simulation of geothermal snow-melting method using foundation pile, Transactions of the Society of Heating, Air- Conditioning and Sanitary Engineers of Japan, Vol.52, (1993), pp.59-69.

4 Miyamoto, S. et al., Snow-melting system using heat stored around foundation piles of bridge through seasons, Bridge and Foundation Engineering, Vol.40, (2006), pp.13-21.

5 Architectural Insitute of Japan, New systems of architecture, 10 Environmental physics, Syokokusha, (1984), p.39.

6 Katto, Y., Dennetsu gairon, Chap.11 Heat transfer involving mass transfer, Yokendo, (1989), p.229.

7 Kojima, K., Snow melting mechanism and heat balance, Meteorological Research Note, No.136, (1979), p.27.

8 Miyamoto, S., Snow-melting and de-icing system on road using natural thermal energy sources, Doctoral Thesis of Nagoya Institute of Technology, (1999), pp.6-8.

9 Takeuchi, M. et al., Numerical simulation of snow-melting system using underground water (effect of water supplying), Proceedings of 39th National Heat Transfer Symposium of Japan, Vol.III, (2002), pp.821-822. 
10 Sugaya, H., Distinction between rain and snow at rainfall during cold season (part III - estimation by wet bulb temperature, Proceedings of 1991 Annual Meeting of the Japanese Society of Snow and Ice, (1991), p.48.

11 Home Page of Japan Meteorological Business Support Center , http://www.jmbsc.or.jp/ 


\section{Figure and Table Captions}

Fig. 1. Outline of a pipe-in-pile snow-melting system

Fig. 2. Ratio of snowfall to rainfall as a function of wet bulb temperature [10]

Fig. 3. Dry density of snowfall as a function of wet bulb temperature

Fig. 4. Accumulated snow fall depth (Fukui 2001)

Fig. 5. Pavement for verification experiment

Fig. 6. Outlet water temperature of heat dissipation pipes

Fig. 7. Averaged heat flux from heat dissipation pipes

Fig. 8. Integrated heat dissipated from heat dissipation pipes per unit snow-melting surface

Fig. 9. Remaining snow depth

Fig. 10(a). Photo of remaining snow situation (2001/1/14)

Fig. 10(b). Simulation result of remaining snow situation (2001/1/14)

Fig. 11(a). Photo of remaining snow situation (2001/1/16)

Fig. 11(b). Simulation result of remaining snow situation (2001/1/16)

Fig. 12. Simulation result of isotherm at cross section of pavement ( (a) $0.5 \mathrm{~m}$ section from inlet and outlet (b) $0.5 \mathrm{~m}$ section from U-turn point

Fig. 13. Surface temperature of pavement at center part

Fig. 14. Water temperature inside heat exchanger pile at $2.9 \mathrm{~m}$ depth

Table 1. Thermal physical properties and characteristic values related to heat transfer used in the simulation 


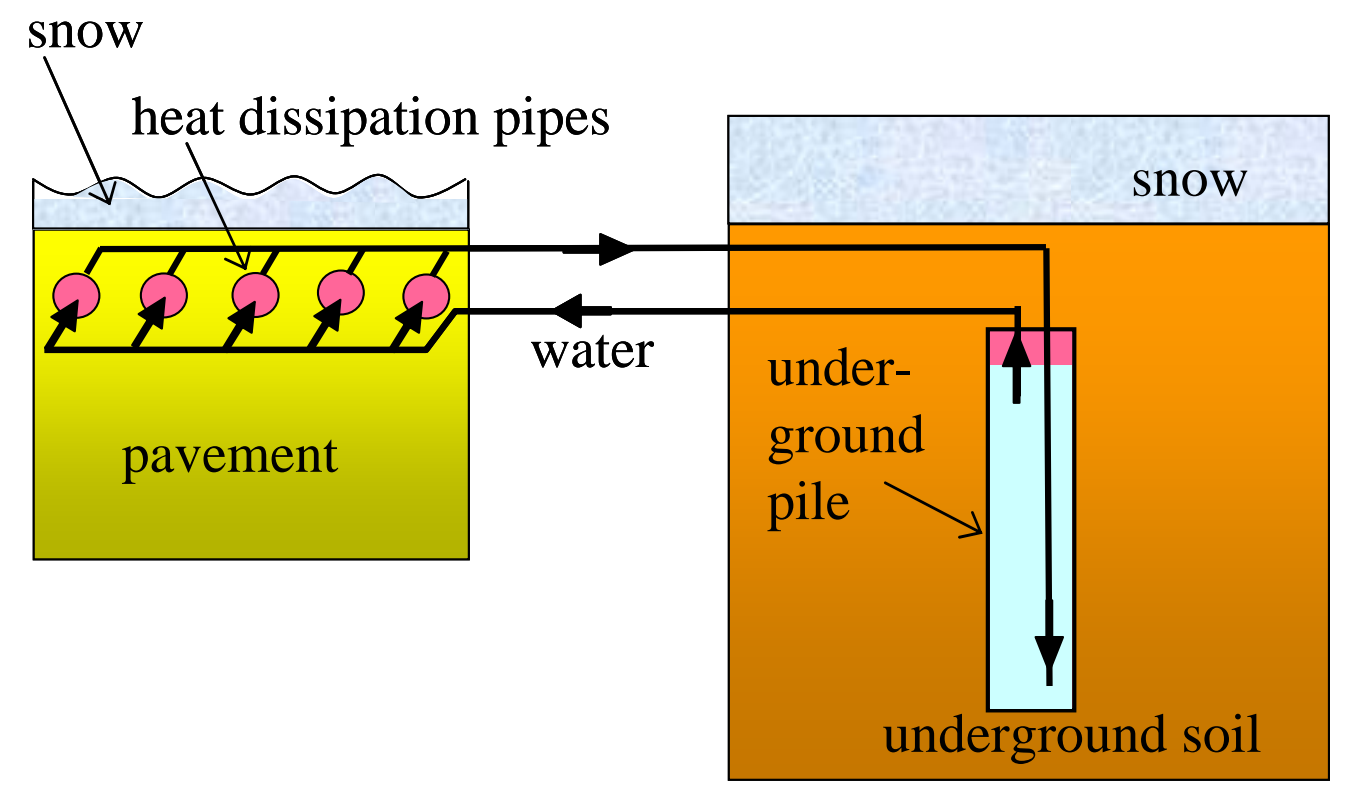

Fig. 1. Outline of a pipe-in-pile snow-melting system 


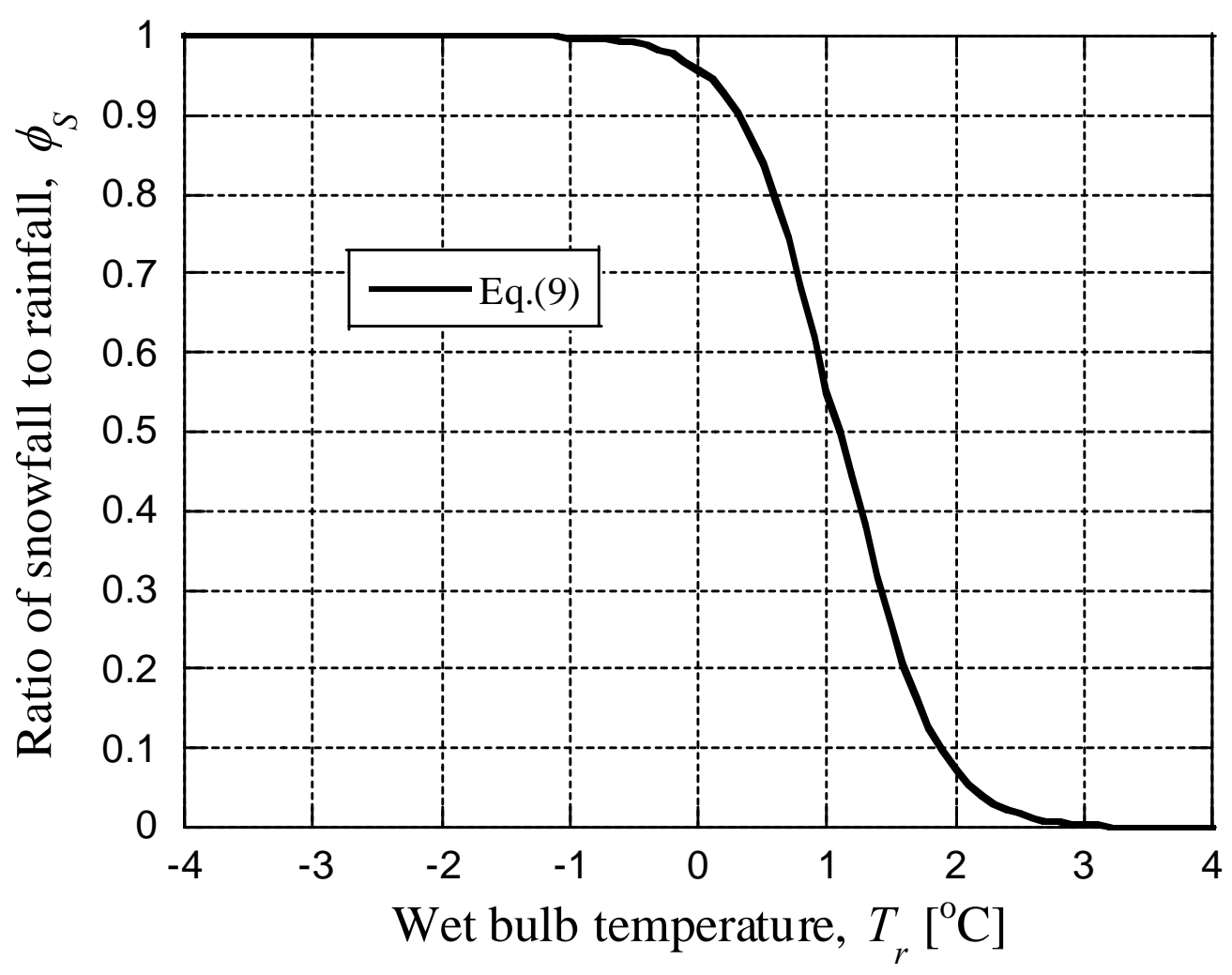

Fig. 2. Ratio of snowfall to rainfall as a function of wet bulb temperature [10] 


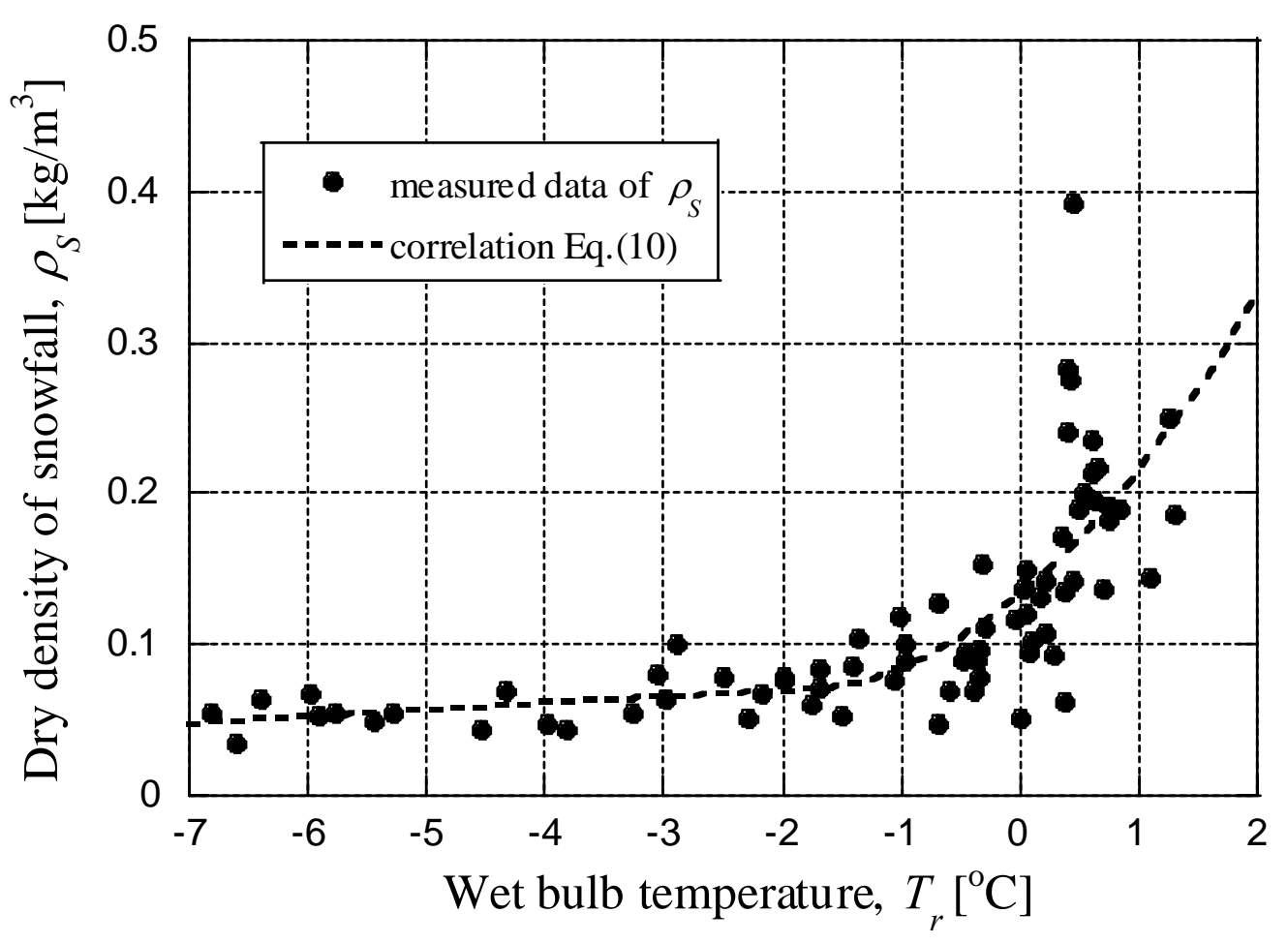

Fig. 3. Dry density of snowfall as a function of wet bulb temperature 


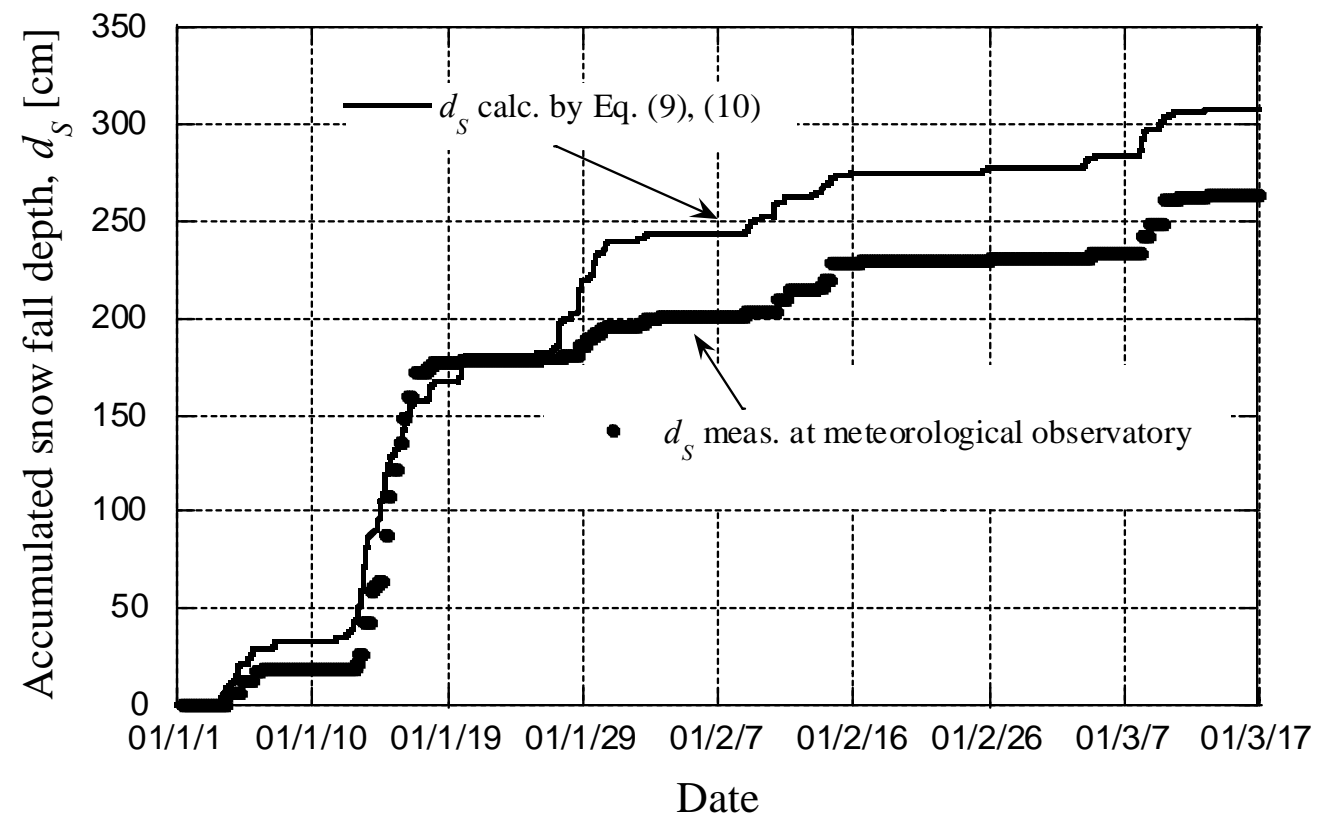

Fig. 4. Accumulated snow fall depth (Fukui 2001) 


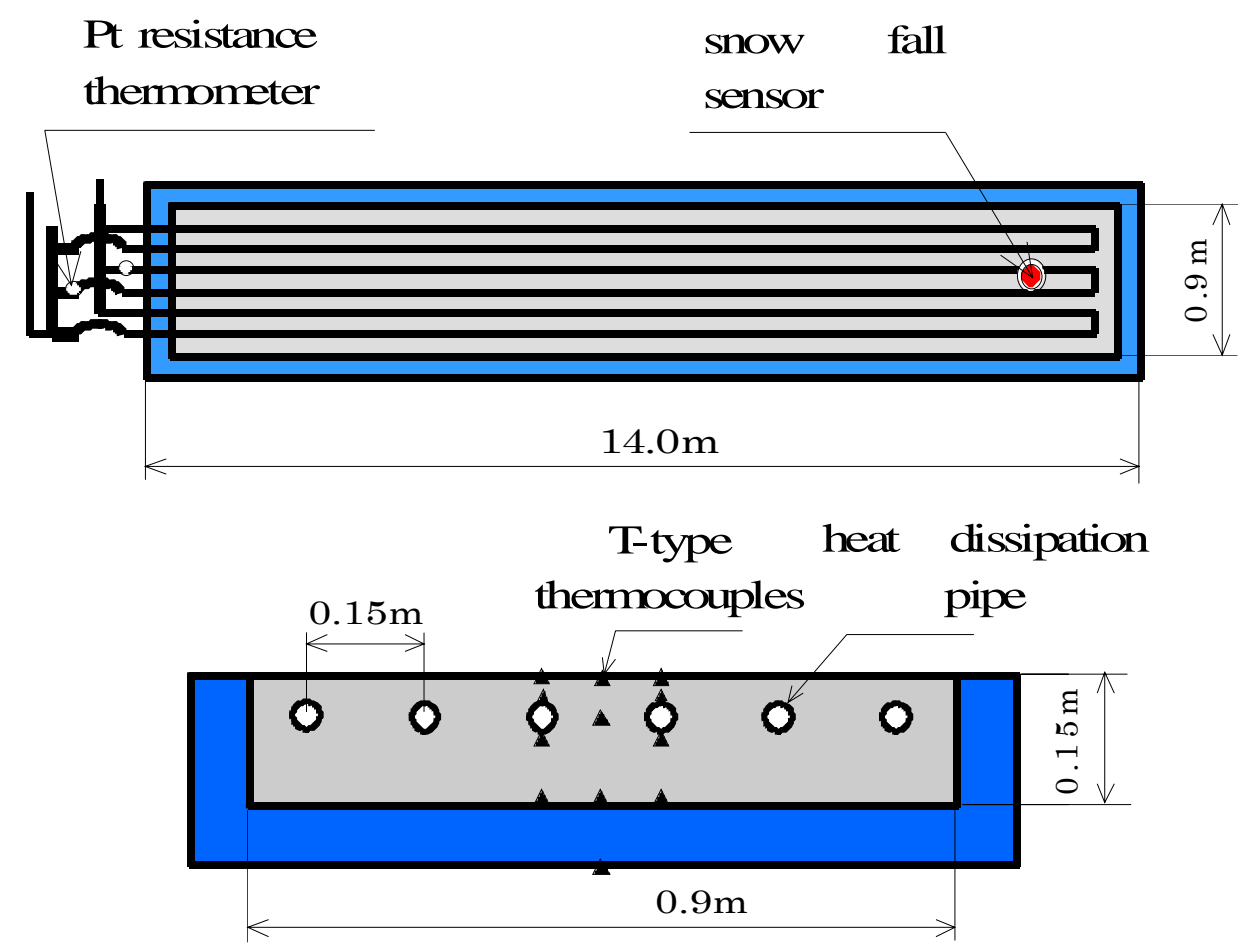

Fig. 5. Pavement for verification experiment 


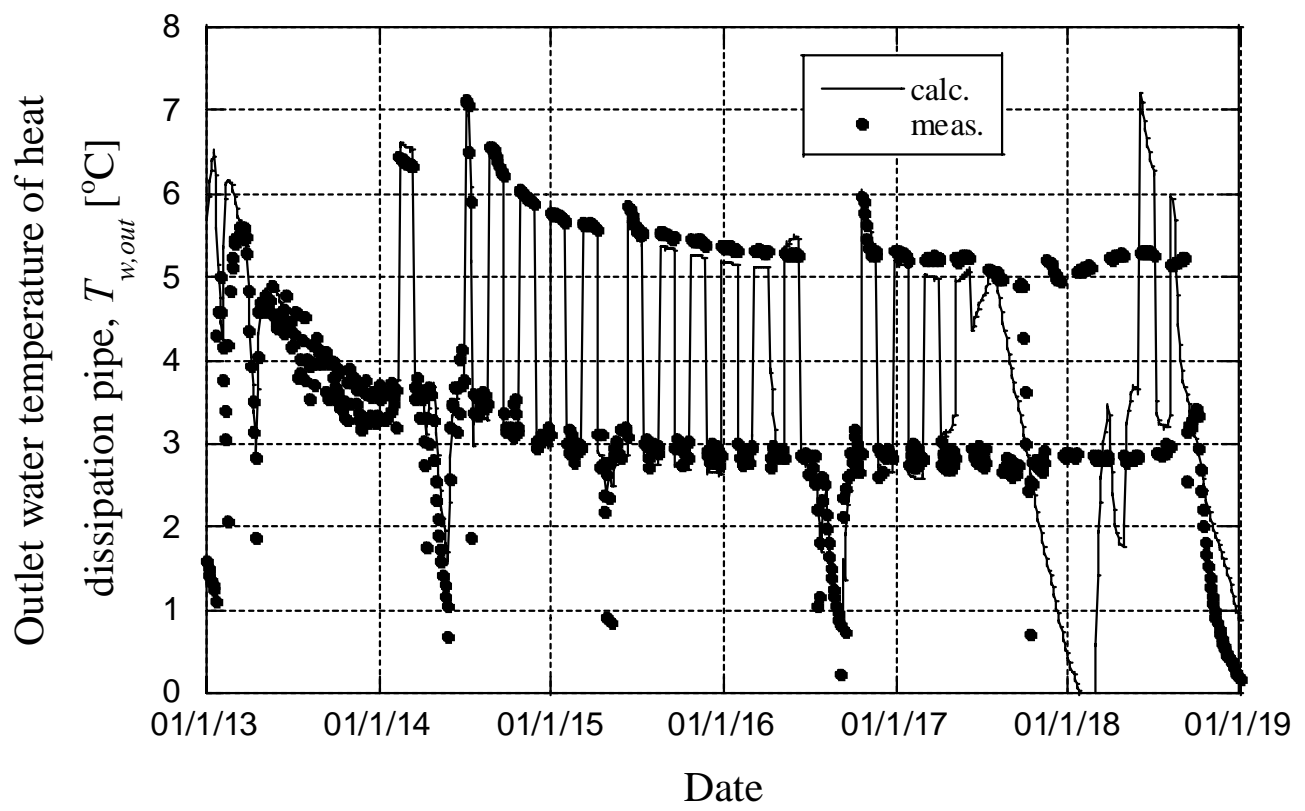

Fig. 6. Outlet water temperature of heat dissipation pipes 


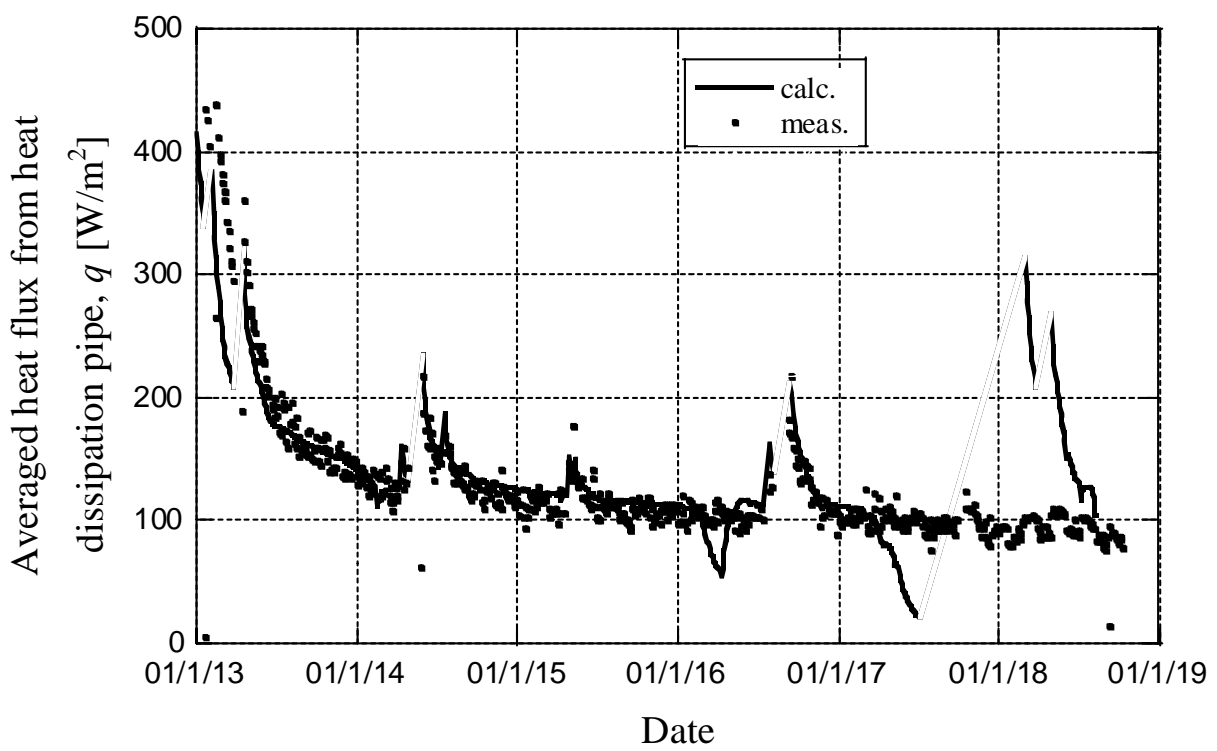

Fig. 7. Averaged heat flux from heat dissipation pipes 


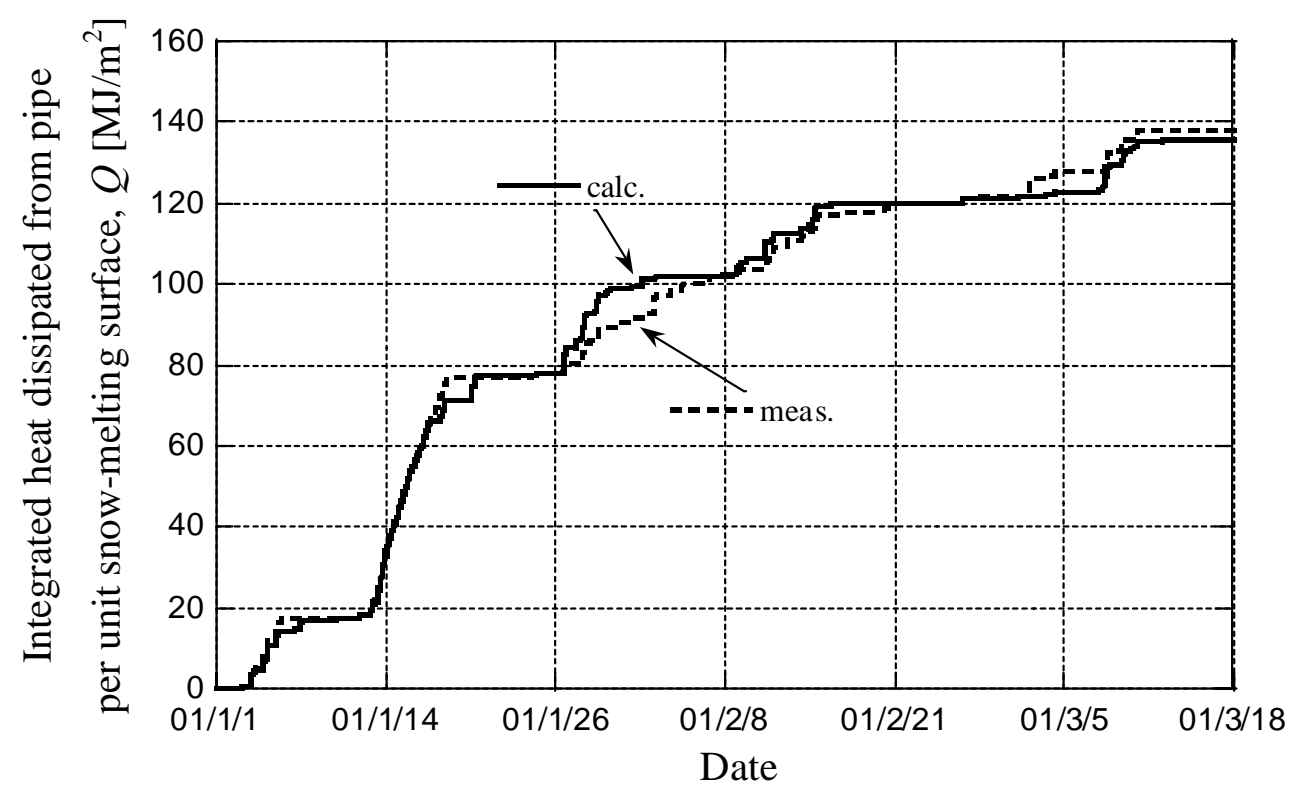

Fig. 8. Integrated heat dissipated from heat dissipation pipes per unit snow-melting surface 


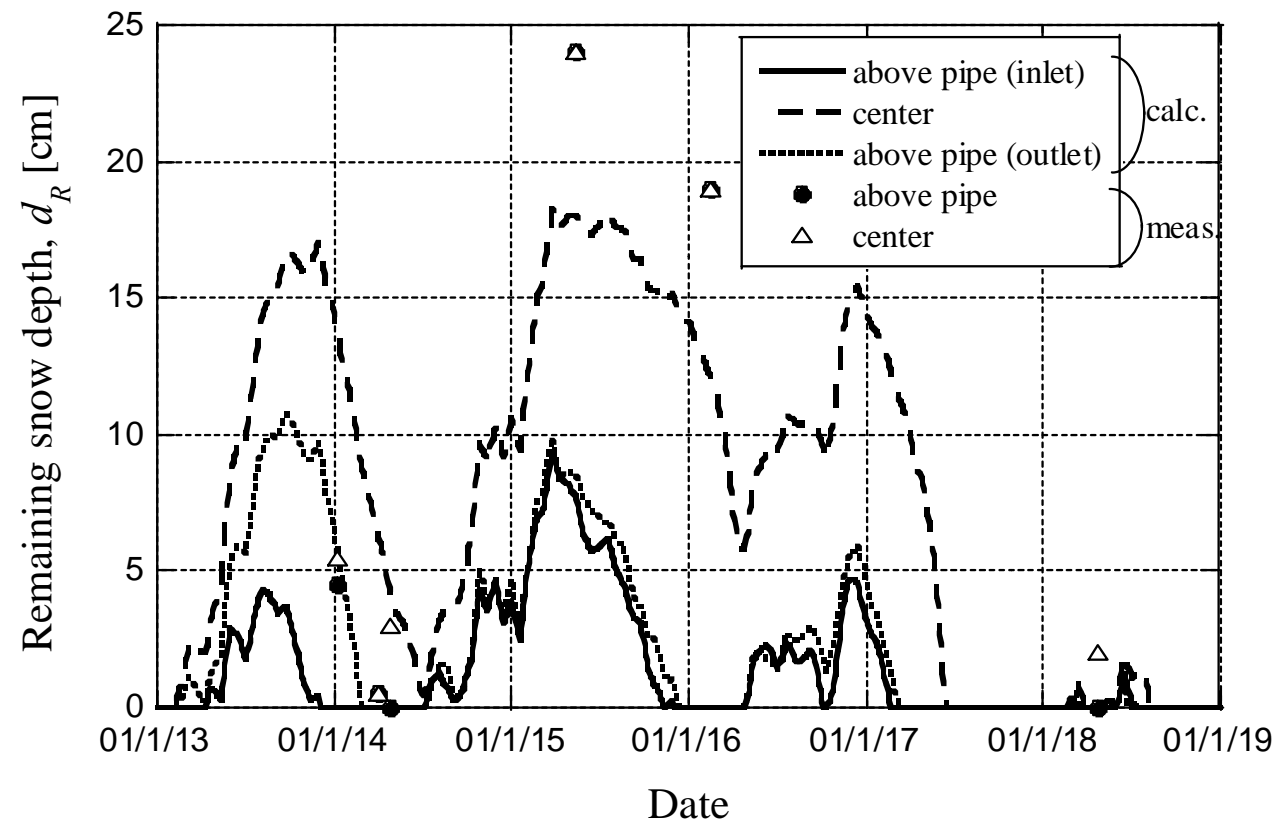

Fig. 9. Remaining snow depth 


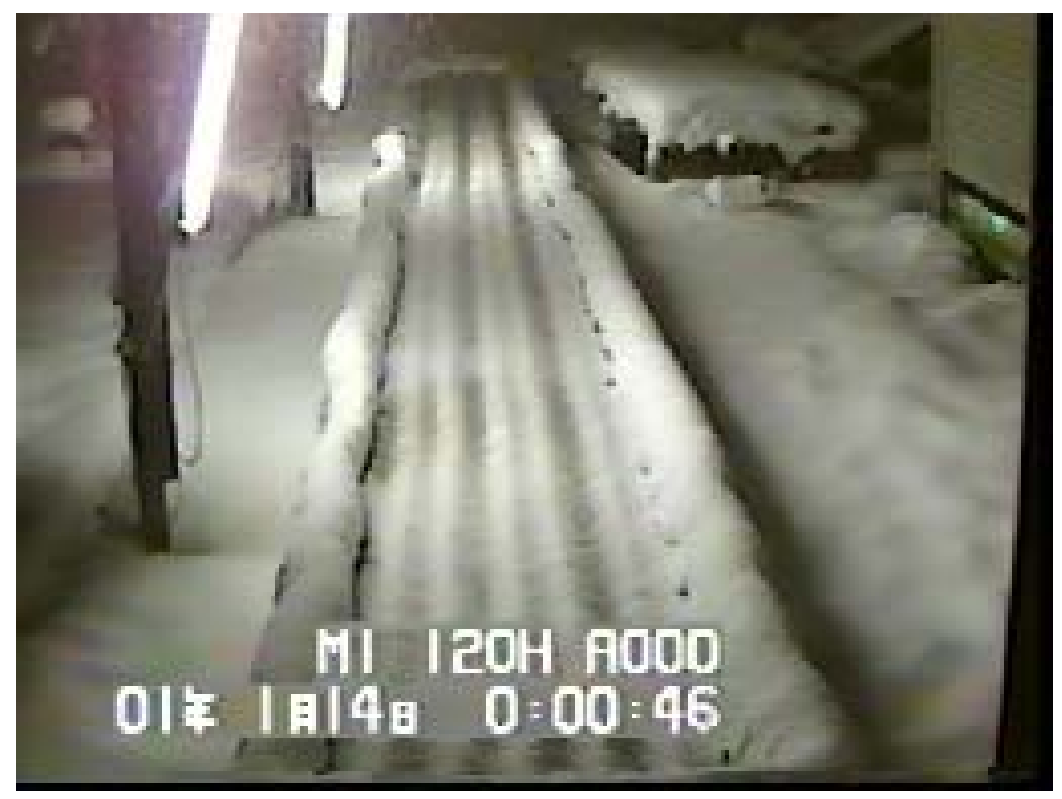

(a) Photo of remaining snow situation (2001/1/14)

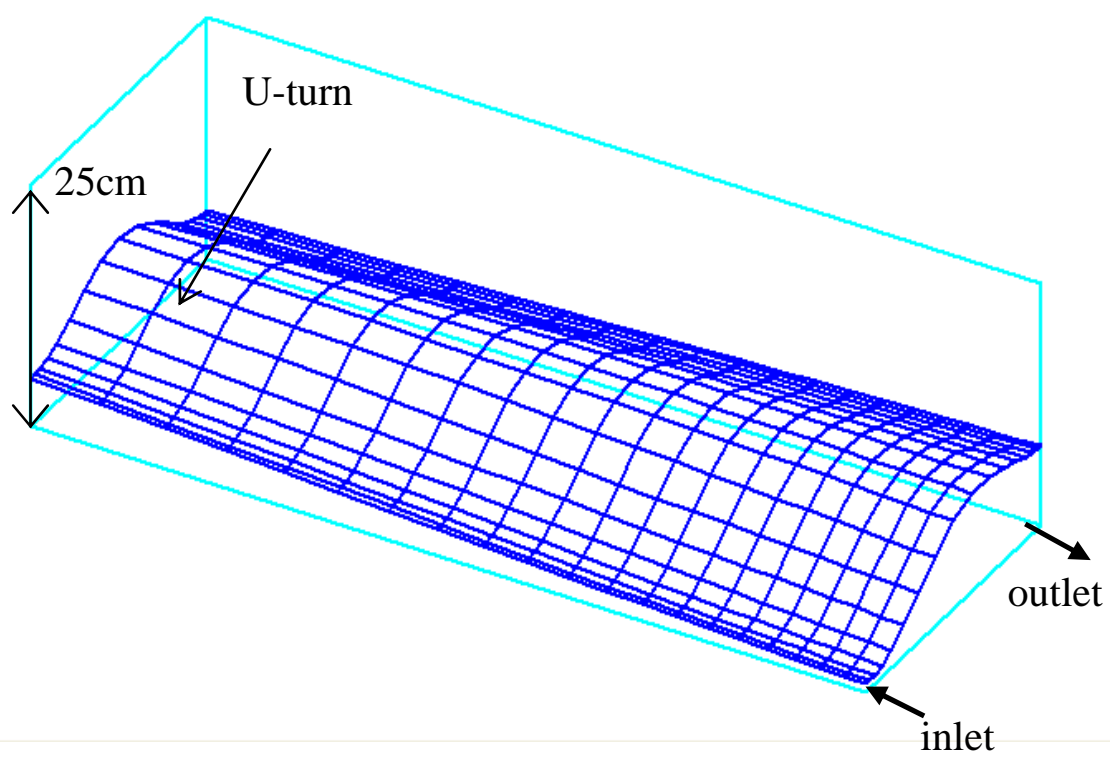

(b) Simulation result of remaining snow situation (2001/1/14) Fig. 10 


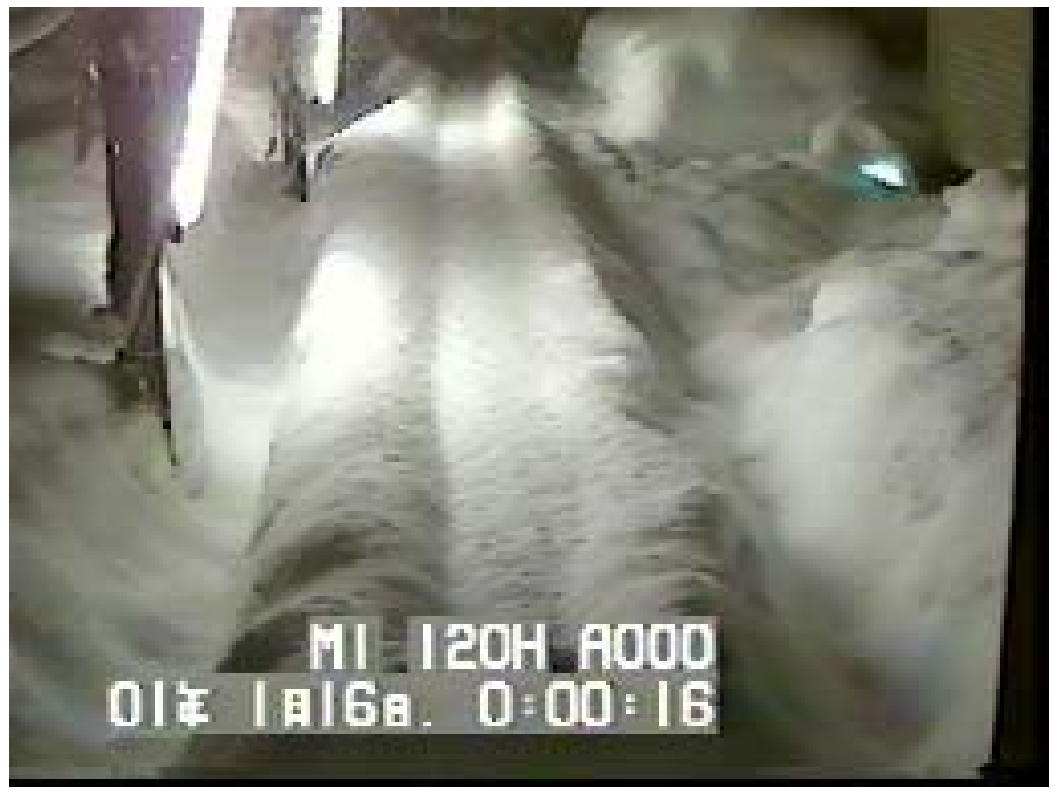

(a) Photo of remaining snow situation (2001/1/16)

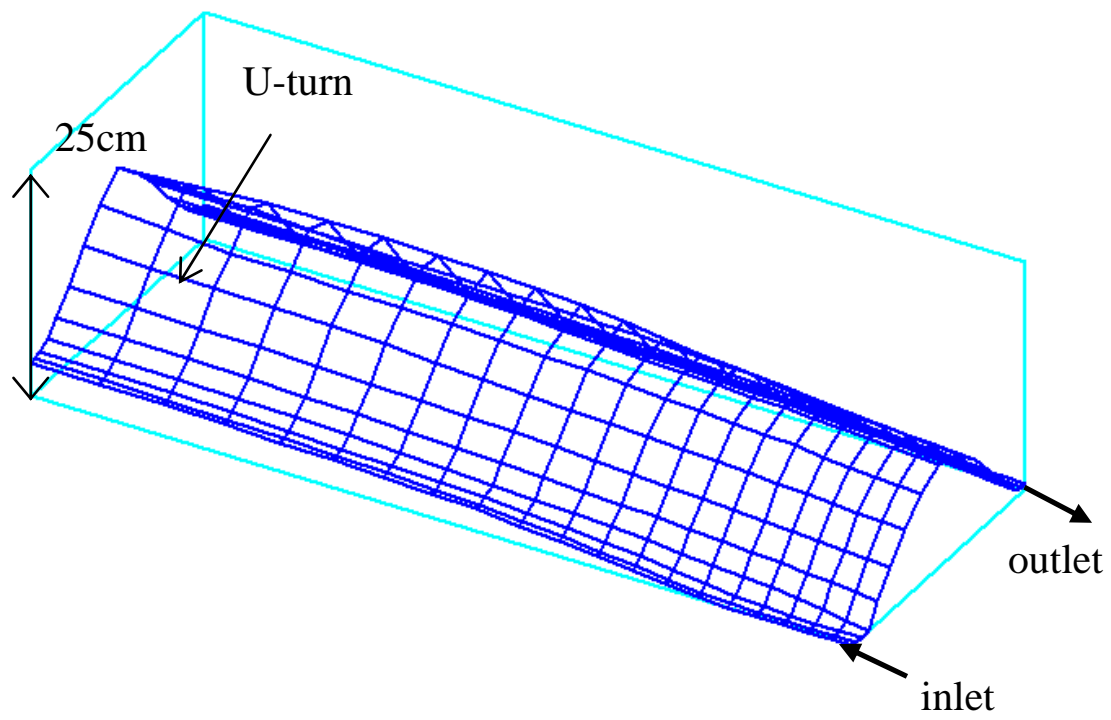

(b) Simulation result of remaining snow situation (2001/1/16) Fig. 11 
(inlet) (outlet) ～(U-turn)
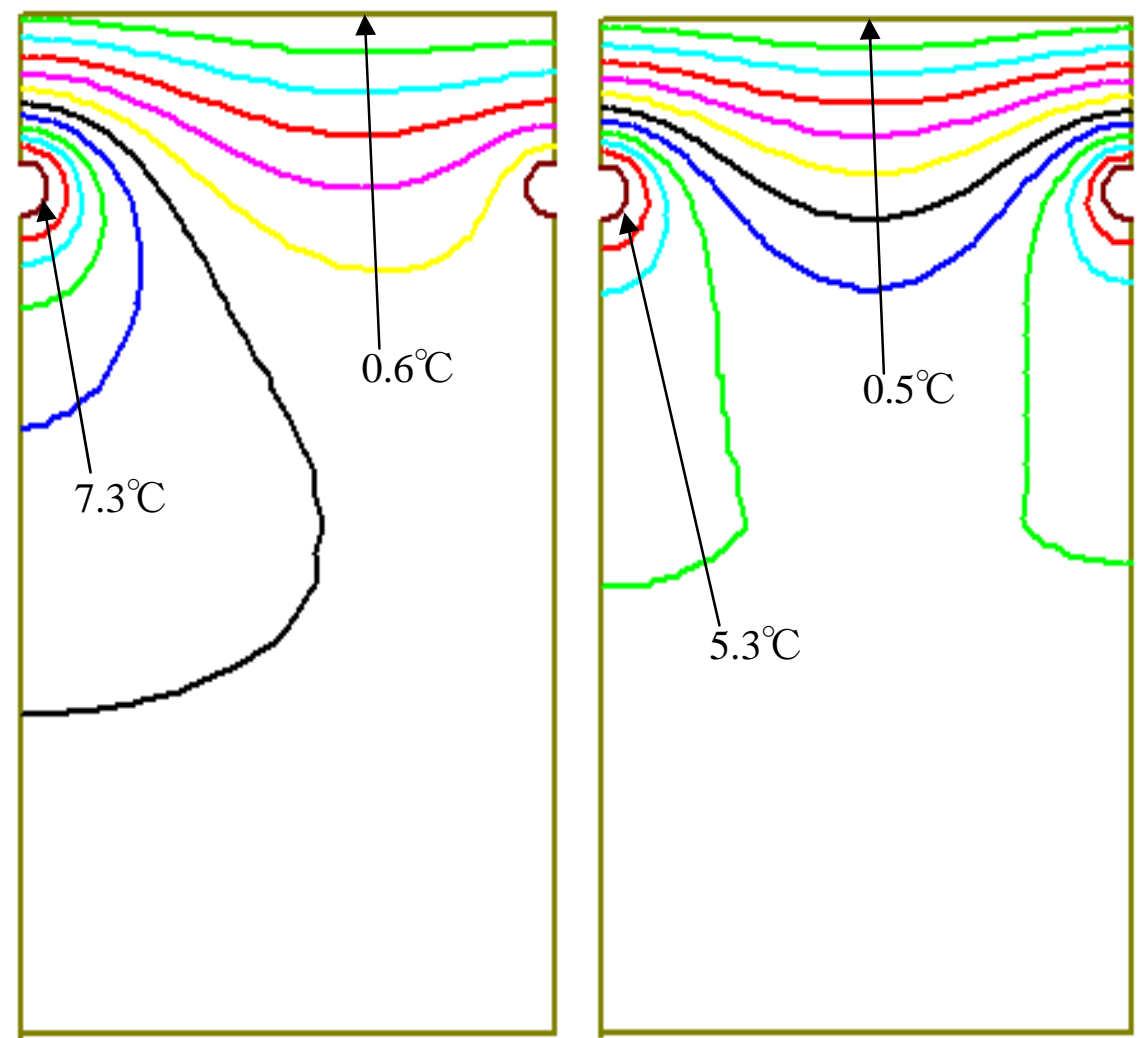

(a)

(b)

Fig. 12 Simulation result of isotherm at cross section of pavement ( (a) $0.5 m$ section from inlet and outlet (b) $0.5 \mathrm{~m}$ section from U-turn point 


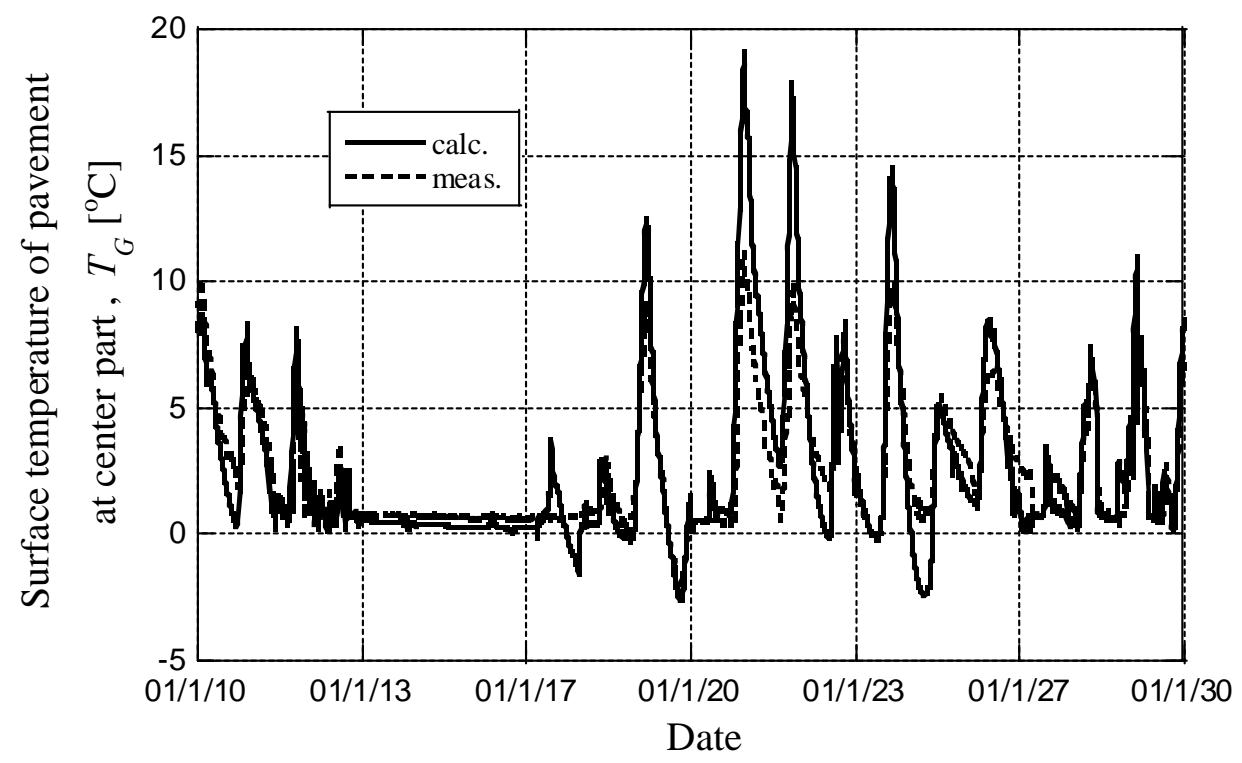

Fig. 13. Surface temperature of pavement at center part 


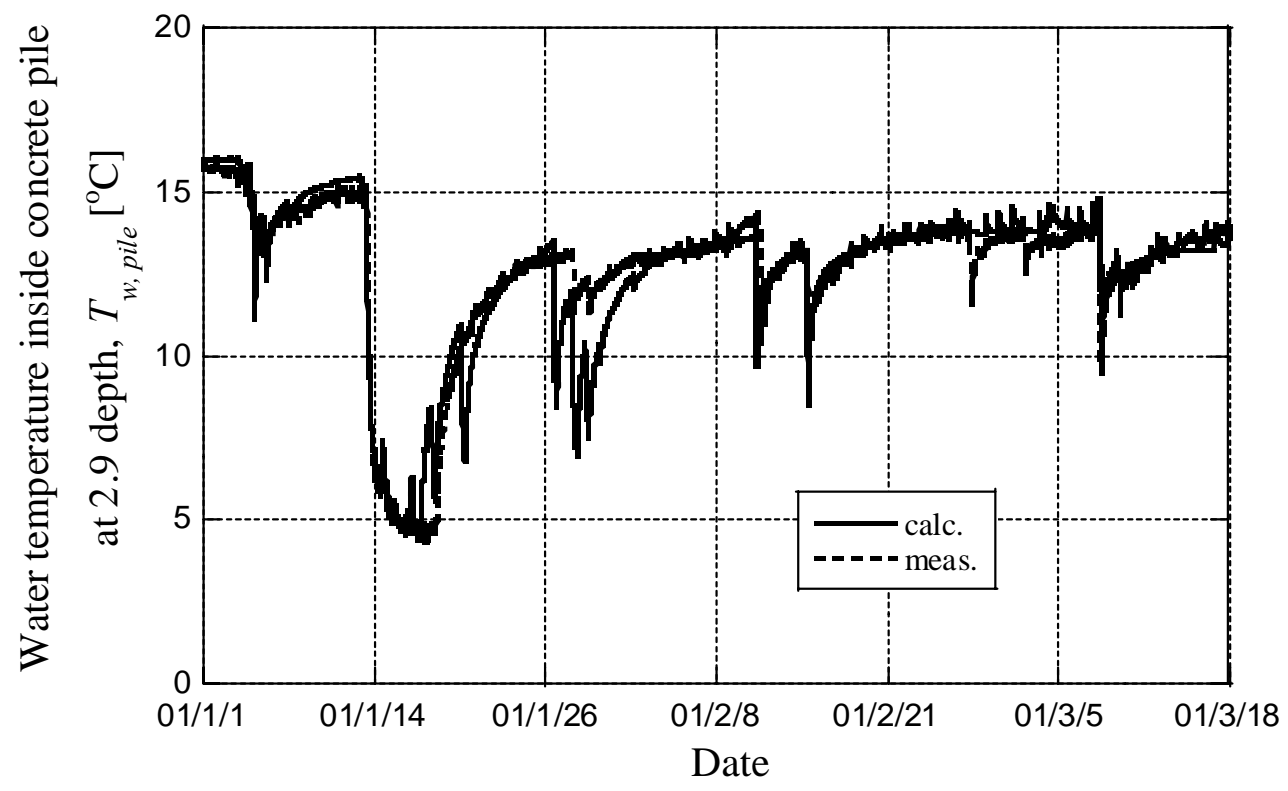

Fig. 14. Water temperature inside heat exchanger pile at $2.9 \mathrm{~m}$ depth 
Table 1. Thermal physical properties and characteristic values related to heat transfer used in the simulation

\begin{tabular}{|c|c|c|c|c|}
\hline pavement & $\begin{array}{l}\text { heat capacity } \\
\text { thermal conductivity }\end{array}$ & $\begin{array}{l}\rho c \\
\lambda\end{array}$ & $\begin{array}{r}2.16 \\
2.8\end{array}$ & $\begin{array}{l}\mathrm{MJ} /\left(\mathrm{m}^{3} \cdot \mathrm{K}\right) \\
\mathrm{W} /(\mathrm{m} \cdot \mathrm{K})\end{array}$ \\
\hline pavement surface & $\begin{array}{l}\text { solar absorptivity (dry condition) } \\
\text { solar absorptivity (wet condition) } \\
\text { emissivity }\end{array}$ & $\begin{array}{l}\alpha_{G} \\
\alpha_{G} \\
\varepsilon_{G}\end{array}$ & $\begin{array}{r}0.72 \\
0.8 \\
0.9\end{array}$ & \\
\hline snow layer & $\begin{array}{l}\text { specific heat } \\
\text { density } \\
\text { thermal conductivity } \\
\text { solar absorptivity } \\
\text { emissivity } \\
\text { heat transfer coefficient between } \\
\text { ground surface and snow layer }\end{array}$ & $\begin{array}{l}c_{S} \\
\rho_{S} \\
\lambda_{S} \\
\alpha_{S} \\
\varepsilon_{S} \\
h_{S}\end{array}$ & $\begin{array}{r}211.7 \\
118 \\
0.074 \\
0.12 \\
0.8 \\
290\end{array}$ & $\begin{array}{l}\mathrm{J} /(\mathrm{kg} \cdot \mathrm{K}) \\
\mathrm{kg} / \mathrm{m}^{3} \\
\mathrm{~W} /(\mathrm{m} \cdot \mathrm{K}) \\
\mathrm{W} /\left(\mathrm{m}^{2} \cdot \mathrm{K}\right)\end{array}$ \\
\hline $\begin{array}{l}\text { heat dissipation } \\
\text { pipe }\end{array}$ & $\begin{array}{l}\text { heat capacity } \\
\text { thermal conductivity } \\
\text { heat transfer coefficient } \\
\text { (flowing) } \\
\text { heat transfer coefficient (still) }\end{array}$ & $\begin{array}{l}\rho c \\
\lambda \\
h \\
h\end{array}$ & $\begin{array}{r}3.65 \\
43 \\
930 \\
10\end{array}$ & $\begin{array}{l}\mathrm{MJ} /\left(\mathrm{m}^{3} \cdot \mathrm{K}\right) \\
\mathrm{W} /(\mathrm{m} \cdot \mathrm{K}) \\
\mathrm{W} /\left(\mathrm{m}^{2} \cdot \mathrm{K}\right) \\
\mathrm{W} /\left(\mathrm{m}^{2} \cdot \mathrm{K}\right)\end{array}$ \\
\hline underground pile & $\begin{array}{l}\text { heat capacity } \\
\text { thermal conductivity }\end{array}$ & $\begin{array}{l}\rho c \\
\lambda\end{array}$ & $\begin{array}{l}4.56 \\
1.83\end{array}$ & $\begin{array}{l}\mathrm{MJ} /\left(\mathrm{m}^{3} \cdot \mathrm{K}\right) \\
\mathrm{W} /(\mathrm{m} \cdot \mathrm{K})\end{array}$ \\
\hline underground soil & $\begin{array}{l}\text { heat capacity } \\
\text { thermal conductivity }\end{array}$ & $\begin{array}{l}\rho c \\
\lambda\end{array}$ & $\begin{array}{l}3.26 \\
1.54\end{array}$ & $\begin{array}{l}\mathrm{MJ} /\left(\mathrm{m}^{3} \cdot \mathrm{K}\right) \\
\mathrm{W} /(\mathrm{m} \cdot \mathrm{K})\end{array}$ \\
\hline soil surface & $\begin{array}{l}\text { solar absorptivity } \\
\text { emissivity }\end{array}$ & $\begin{array}{l}\alpha_{G} \\
\varepsilon_{G}\end{array}$ & $\begin{array}{l}0.7 \\
0.9\end{array}$ & \\
\hline
\end{tabular}

